\title{
Astaxanthin Pretreatment Attenuates Hepatic Ischemia Reperfusion-Induced Apoptosis and Autophagy via the ROS/MAPK Pathway in Mice
}

\author{
Jingjing Li ${ }^{1}$, Fan Wang ${ }^{1}$, Yujing Xia ${ }^{1}$, Weiqi Dai ${ }^{1}$, Kan Chen ${ }^{1}$, Sainan Li ${ }^{1}$, Tong Liu ${ }^{1}$, \\ Yuanyuan Zheng ${ }^{1}$, Jianrong Wang ${ }^{2}$, Wenxia Lu ${ }^{2}$, Yuqing Zhou ${ }^{3}$, Qin Yin ${ }^{3}$, Jie Lu ${ }^{1}$, \\ Yingqun Zhou ${ }^{1, *}$ and Chuanyong Guo ${ }^{1, *}$
}

1 Department of Gastroenterology, Shanghai Tenth People's Hospital, Tongji University School of Medicine, Shanghai 200072, China; E-Mails: sealjj@126.com (J.L.); fairywong04285@163.com (F.W.); gagaxyj@126.com (Y.X.); dai_yue@163.com (W.D.); cutking@126.com (K.C.); Lrk678@126.com (S.L.); klmn1334@sina.com (T.L.); sxzhengyuanyuan@126.com (Y.Z.); kennisren@hotmai.com (J.L.)

2 The First Clinical Medical College of Nanjing Medical University, Nanjing 210029, China; E-Mails: hellowangjr@163.com (J.W.); 15214327248@163.com (W.L.)

3 The First Affiliated Hospital of Soochow University, Suzhou 215006, China; E-Mails: zyq937065339@163.com (Y.Z.); yinqin201011@163.com (Q.Y.)

* Authors to whom correspondence should be addressed; E-Mails: 13342471jj@tongji.edu.cn (Y.Z.); 1962cy_guo@tongji.edu.cn (C.G.); Tel.: +86-21-6630-0588 (Y.Z.); +86-21-6630-2535 (C.G.); Fax: +86-21-6630-3983 (C.G.).

Academic Editor: Paul Long

Received: 23 March 2015 / Accepted: 19 May 2015 / Published: 27 May 2015

\begin{abstract}
Background: Hepatic ischemia reperfusion (IR) is an important issue in complex liver resection and liver transplantation. The aim of the present study was to determine the protective effect of astaxanthin (ASX), an antioxidant, on hepatic IR injury via the reactive oxygen species/mitogen-activated protein kinase (ROS/MAPK) pathway. Methods: Mice were randomized into a sham, IR, ASX or IR + ASX group. The mice received ASX at different doses $(30 \mathrm{mg} / \mathrm{kg}$ or $60 \mathrm{mg} / \mathrm{kg}$ ) for 14 days. Serum and tissue samples at $2 \mathrm{~h}, 8 \mathrm{~h}$ and $24 \mathrm{~h}$ after abdominal surgery were collected to assess alanine aminotransferase (ALT), aspartate aminotransferase (AST), inflammation factors, ROS, and key proteins in the MAPK family. Results: ASX reduced the release of ROS and cytokines leading to inhibition of apoptosis and autophagy via down-regulation of the activated phosphorylation of related
\end{abstract}


proteins in the MAPK family, such as P38 MAPK, JNK and ERK in this model of hepatic IR injury. Conclusion: Apoptosis and autophagy caused by hepatic IR injury were inhibited by ASX following a reduction in the release of ROS and inflammatory cytokines, and the relationship between the two may be associated with the inactivation of the MAPK family.

Keywords: hepatic ischemia reperfusion; oxidative stress; astaxanthin; reactive oxygen species

\section{Introduction}

Hepatic ischemia reperfusion (IR) injury generally occurs in hemorrhagic shock, liver transplantation and other medical conditions and is a pathophysiological process influencing liver function after hepatic resection and severe trauma [1,2]. Whether hepatic IR injury can be effectively avoided is important in limiting progress in hepatobiliary surgery. Though the concept of IR was first proposed in 1960 by Jennings [3], there are still no effective prevention methods due to its complicated mechanism, although studies have shown that its development is related to liver Kupffer cells, reactive oxygen species (ROS), calcium overload, and inflammatory cytokines [4-6]. Research demonstrated that Toll-like receptor (TLR) stimulation by IR may play an important role in the development of new therapeutic strategies in liver Kupffer cells [7-9]. Therefore, the therapy of hepatic IR has become a focus of attention in the medical community.

Ischemia reperfusion is a multifactorial process and includes major oxidative stress induced by ischemia and hypoxia [10]. Under normal physiological conditions, the production and elimination of oxygen free bases is dynamically balanced. However, endothelial cells and Kupffer cells activated by oxidative stress can generate large numbers of ROS through nicotinamide adenine dinucleotide phosphate (NADPH) in the membrane, and ROS damage liver cells by changing the permeability of the cell membrane, causing lipid peroxidation or directly increasing neutrophil microcirculation [10-12]. In addition, cytokines such as TNF- $\alpha$ and IL-6, released by activated Kupffer cells and aggregated neutrophils, also play a key role in IR injury [13]. TNF- $\alpha$ promotes swelling of endothelial cells to activate ROS, while IL-6 can induce hepatocyte injury to produce C-reactive protein, $\alpha$-trypsin and fibrinogen which are associated with the MAPK family, and the PI3K/Akt and HMGB1 pathways [14-16]. Kohli and colleagues found that the death of liver sinusoidal endothelial cells and hepatocytes was by apoptosis, and intrinsic apoptosis induced by the explosion of ROS and inflammatory cytokines resulted in a mitochondrial energy metabolism disorder which may lead to hepatic IR injury [2,17]. However, the ratio of pro-apoptotic Bax and anti-apoptotic Bcl-2, located in the outer membrane, in mitochondrial apoptosis determines cell survival and death by controlling the opening and closing of the mitochondrial permeability transition pore (MPTP), as described by Selzner, Imahashi and colleagues $[18,19]$.

Autophagy, another type of programmed cell death, has significant differences in biochemical pathways and morphology compared with apoptosis. Recent studies have found that autophagy can be regulated by a molecular mechanism and coordination with apoptosis to promote cell death [20]. Forty years ago, Sybers and colleagues first observed an increase in autophagic vacuoles following IR [21]. In addition, autophagy induced by cardiac ischemia and strengthened by reperfusion injury was found in rabbits by Decker et al. [22]. These studies provided a strong basis for the role of autophagy in hepatic 
IR. In 1998, Liang et al. demonstrated that elimination of the autophagy gene, Beclin-1, could inhibit the replication of the Sindbis virus when it was combined with Bcl-2, the decline of which promoted autophagy [23]. Therefore, the mechanism of hepatic IR injury may be further elucidated by evaluating the interaction between autophagy and apoptosis.

As autophagy and apoptosis are induced by the release of ROS, this is important in the IR injury process, and scavenging ROS may be a target when screening drugs. Astaxanthin (3,3'-dihydroxy- $\beta$, $\beta^{\prime}$-carotene-4,4'-dione, ASX), a carotenoid which is found in fresh-water microalgae and marine organisms including phytoplankton and fish, has higher antioxidant activity than lutein, $\alpha$-carotene and $\beta$-carotene [24]. The anti-lipid oxidation, anti-inflammation, anti-diabetes and anti-cancer effects of ASX have aroused increased attention both nationally and internationally [25-27]. Research has shown that ASX can exert strong antioxidant activity by quenching singlet oxygen and purifying free radicals in ulcer and hepatic stellate cells [28,29]. In alveolar epithelial cells, ASX blocked ROS generation and dose-dependently inhibited apoptosis through a mitochondrial signaling pathway, as shown by Song and colleagues [30]. ASX treatment has been shown to have therapeutic properties, as U937 cells were protected from oxidative stress caused by lipopolysaccharide thus reducing ROS production [31]. In other system diseases, tissues and cells, ASX also effectively resisted oxidative stress via the inhibition of ROS release caused by UVB in human keratinocytes, neutrophils treated with free fatty acids and high glucose, and by alloxan in diabetic rats [32-34]. With respect to IR, Lu, Shen and Lauver showed the protective effects of ASX on brain and myocardial injury following IR [35-37]. However, in hepatocellular injury following IR, Gulten et al. found that ASX treatment significantly decreased the conversion of xanthine dehydrogenase $(\mathrm{XDH})$ to xanthine oxidase $(\mathrm{XO})$, which reduced the level of oxidative stress [38]. In another study, Ping et al. illustrated that cryptotanshinone alleviated liver IR injury via anti-mitochondrial apoptosis [39]. It is unknown whether ASX can protect hepatocytes by directly reducing ROS and the pathways mediating the interaction between ROS, apoptosis and autophagy.

The aim of the present study was to determine the protective mechanism of ASX on hepatic IR injury. It is hypothesized that ASX pretreatment can attenuate ROS production induced by IR to down-regulate apoptosis and autophagy and achieve liver function protection and rapid injury recovery.

\section{Results and Discussion}

\subsection{ASX Had No Effect on Normal Liver Tissue}

Before validation of the protective effects of ASX on hepatic IR injury, we first determined the influence of ASX on normal liver tissue. The same number of mice were given the same volume of saline, olive oil or ASX (30 mg/kg or $60 \mathrm{mg} / \mathrm{kg}$ ) for 14 days, respectively. Serum and liver tissues were obtained from the mice to examine liver function, pathology and markers related to damage (Bcl-2, Bax, Beclin-1 and LC3) using biochemical methods, PCR detection and western blot. The results showed that the expression of serum liver enzymes in the four groups was close to normal levels (Figure 1A), while at the gene and protein levels, differences in relevant autophagic and apoptotic indicators were not obvious (Figures 1B,C). Finally, we identified pathological and morphological changes in the ASX groups. The cell structures showed small disturbances, which may have been due to the influence of 
drug metabolism, and liver function and protein expression in the related pathways showed no significant effects (Figure 1D). Thus, ASX and olive oil had no significant effect on normal liver tissue.

A
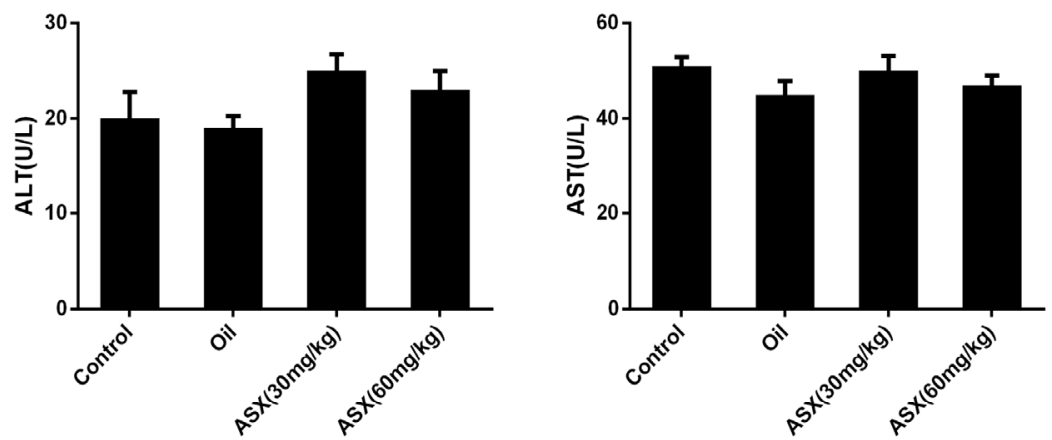

B

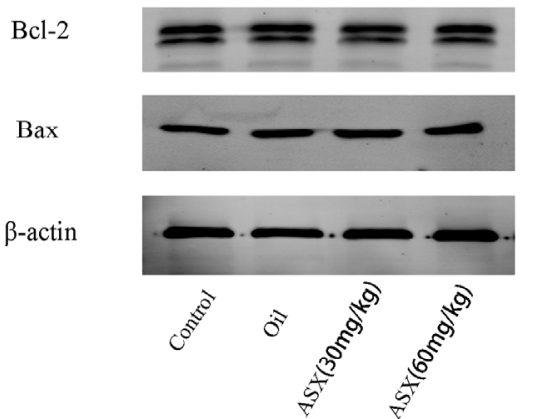

Beclin-1

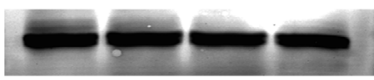

LC3

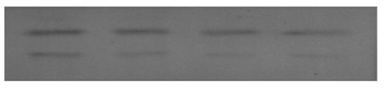

$\beta$-actin

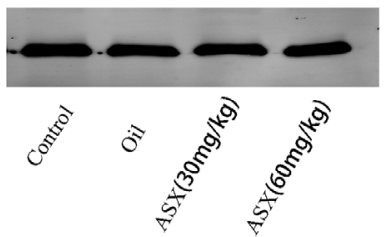

C

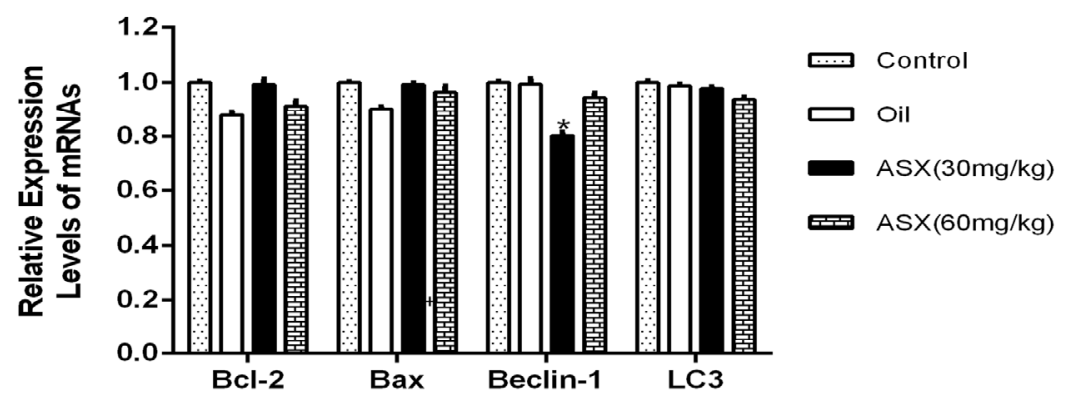

$\mathrm{D}$

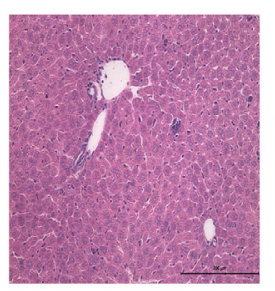

Control

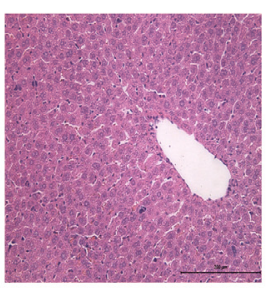

Oil

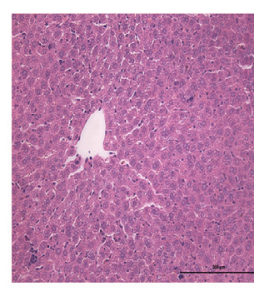

ASX (30mg/kg)

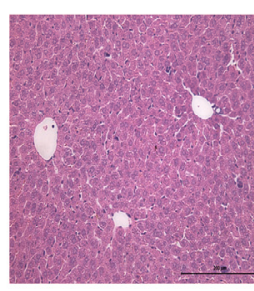

ASX $(60 \mathrm{mg} / \mathrm{kg})$

Figure 1. ASX had no injurious effects on liver tissue. (A) ALT and AST were expressed as the mean \pm SD of 8 mice per group; (B) western blots of the expression of Bcl-2, Bax, Beclin-1 and LC3 are shown by gray bands; (C) the mRNA expression of Bcl-2, Bax, Beclin-1 and LC3 was assessed by real time PCR. The experiments were repeated three times and data are presented as the mean \pm SD. ${ }^{*} p<0.05$ for ASX $(30 \mathrm{mg} / \mathrm{kg}) v s$. oil; (D) representative hematoxylin and eosin (HE) stained sections of liver shown by digital microscopy. Original magnifications: $200 \times$. 
A
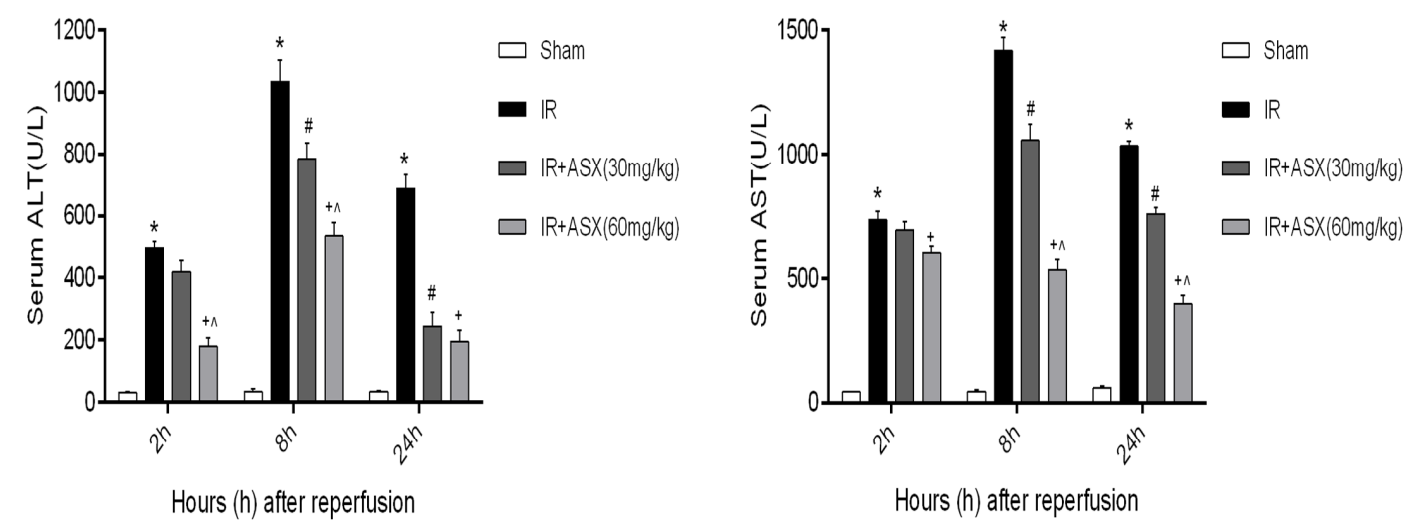

$\mathrm{B}$
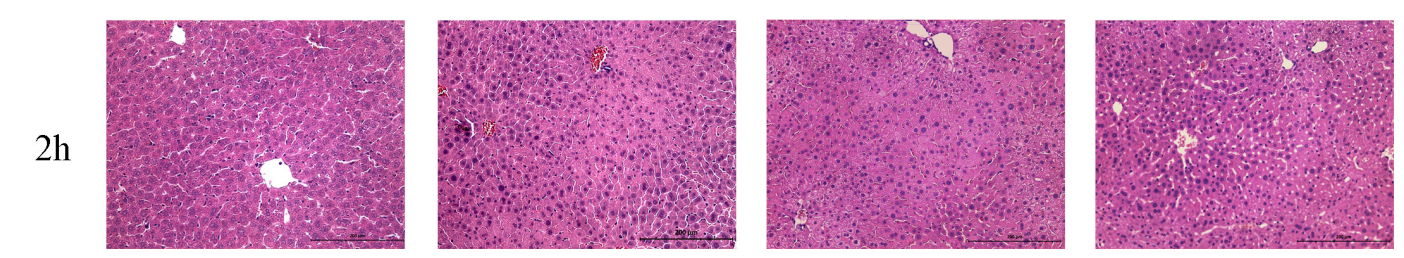

$8 \mathrm{~h}$


Sham

IR

$\operatorname{IR}+\operatorname{ASX}(30 \mathrm{mg} / \mathrm{kg})$

$\mathrm{IR}+\mathrm{ASX}(60 \mathrm{mg} / \mathrm{kg})$

Figure 2. ASX pretreatment ameliorates hepatic IR injury. (A) ALT and AST were expressed as the mean \pm SD of 6 mice per group. ${ }^{*} p<0.05$ for IR $v s$. sham, ${ }^{*} p<0.05$ for $\mathrm{IR}+\operatorname{ASX}(30 \mathrm{mg} / \mathrm{kg}) v s . \mathrm{IR},{ }^{+} p<0.05$ for IR $+\operatorname{ASX}(60 \mathrm{mg} / \mathrm{kg}) v s . \mathrm{IR},{ }^{\wedge} p<0.05$ for IR + ASX (60 mg/kg) vs. IR + ASX (30 mg/kg); (B) Representative hematoxylin and eosin (HE) stained liver sections are shown by digital microscopy. Original magnifications: $200 \times$.

\subsection{ASX Pretreatment Ameliorates Hepatic IR Injury Including Liver Enzymes and Pathology}

ALT and AST are important indicators of liver dysfunction and are found in the hepatocyte cytoplasm. When necrosis occurs in liver cells, ALT and AST may rise rapidly and are sensitive measurements. In our experiment, $2 \mathrm{~h}, 8 \mathrm{~h}$ and $24 \mathrm{~h}$ were the main observation time points for measuring ALT, AST and pathological changes. The results showed that the enzymes in the IR group were significantly increased compared with the sham group at each point, and this was particularly evident at $8 \mathrm{~h}$. Following ASX treatment (30 mg/kg or $60 \mathrm{mg} / \mathrm{kg}$ ), ALT and AST decreased in a dose-dependent 
manner (Figure 2A). These findings suggested that ASX can protect liver function and this effect was dependent on dose. To illustrate this, we used HE staining to observe pathological changes in liver tissue sections. At $2 \mathrm{~h}$, only a small amount of nuclear enrichment with no significant necrosis was observed in the IR group. However, disorganized liver form, complete destruction of cell structure, disordered lobular structure and marked hepatocyte necrosis were seen at $8 \mathrm{~h}$ and $24 \mathrm{~h}$. The low ASX concentration $(30 \mathrm{mg} / \mathrm{kg})$ reduced the necrotic area, while the high ASX concentration $(60 \mathrm{mg} / \mathrm{kg})$ showed a greater protective effect (Figure 2B).

\subsection{ASX Reduced the Release of Inflammatory Factors Including TNF- $\alpha$ and IL-6}

Ischemia reperfusion of tissues can promote the release of oxygen free radicals and related inflammatory factors (TNF- $\alpha$, IL-6) which aggravate the injury of endothelial cells leading to liver microcirculation disturbance via chemotaxis [2]. Therefore, we selected ASX at the dose of $60 \mathrm{mg} / \mathrm{kg}$ to determine TNF- $\alpha$ and IL- 6 in the serum and tissues of mice, respectively, using ELISA, real time PCR, western blot and histochemical staining techniques. The results showed that the expression of TNF- $\alpha$ and IL- 6 increased in the IR group not only in plasma but in the tissues. The ELISA results on serum levels demonstrated that TNF- $\alpha$ and IL-6 showed an increasing trend and peaked at $8 \mathrm{~h}$. ASX reduced the release of TNF- $\alpha$ and IL-6 at each time point (Figure 3A). Figure 3B,C shows the gene and protein levels of TNF- $\alpha$ and IL-6. Compared with the sham group, the gene and protein levels of TNF- $\alpha$ and IL- 6 increased in the IR group with the greatest effect of ASX seen at $8 \mathrm{~h}$. We selected tissue slices at the $8 \mathrm{~h}$ period for immunohistochemical staining. The integral optical density of yellow granules was used to show severity, which was consistent with the mRNA and protein expression described above (Figure 3D). The results for plasma content, mRNA levels, protein expression and tissue staining provided strong evidence that ASX inhibited the production of inflammatory cytokines, such as TNF- $\alpha$ and IL-6, in serum and tissue.

\subsection{ASX Alleviated Apoptosis and Autophagy by Reducing the Bax/Bcl-2 Ratio}

Autophagy and apoptosis are preconditions which cause necrosis of the liver. Interrelation and distinction between them commonly play a key role in the ischemia reperfusion process. Therefore, we amplified the gene and assessed the protein expression of Bcl-2 and Bax during apoptosis, and Beclin-1 and LC3 during autophagy. ASX promoted the level of anti-apoptotic Bcl-2 but inhibited the pro-apoptotic Bax, leading to a decline in the ratio of Bax and Bcl-2 as shown by real-time PCR and western blot. Autophagy-related proteins, such as Beclin-1 and LC3, significantly increased due to disordered energy metabolism after IR and ASX reduced the damage caused by autophagy-induced cell necrosis (Figure 4A,B). These results were verified by histochemical staining (Figure 4C). In addition, detection of autophagosomes was carried out by electron microscopy (Figure 4D). Compared with the sham group, the autophagic vacuoles of the IR group were markedly increased. Following ASX administration, the agglutinated chromatin, damaged mitochondria and autophagy corpuscles were not easily seen. Taken together, these results demonstrated that ASX inhibited apoptosis and autophagy to protect hepatocytes from necrosis. 
A
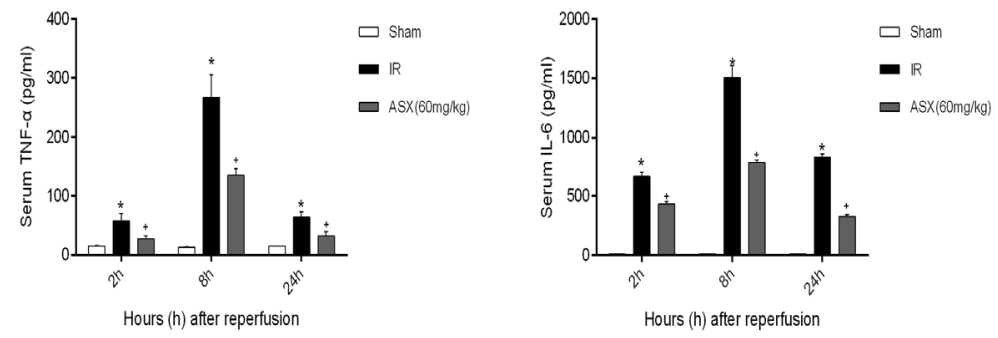

B
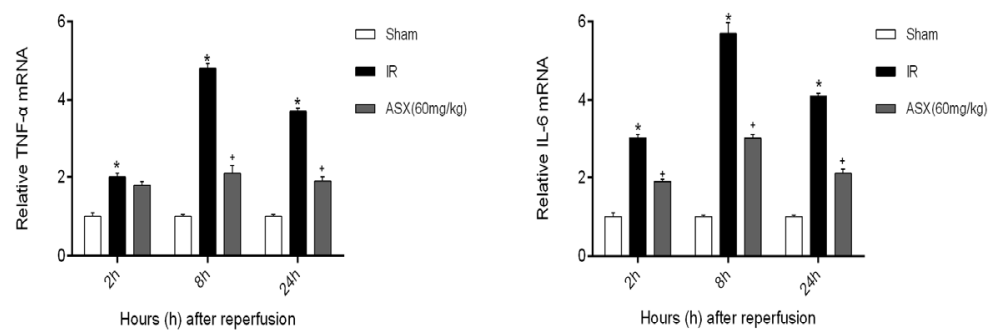

C

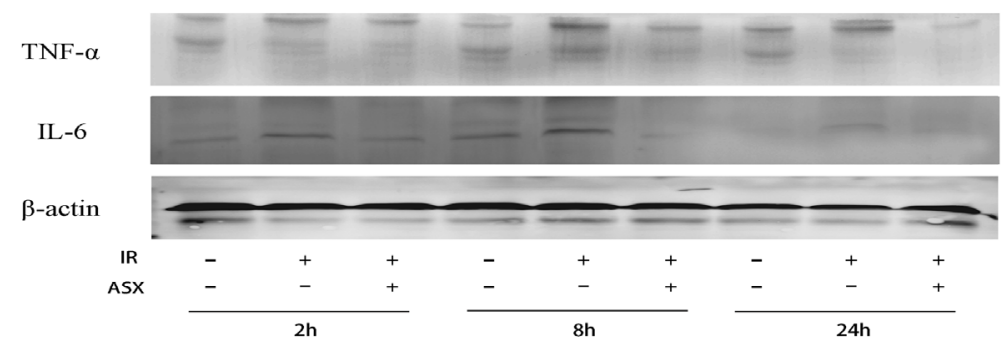

D
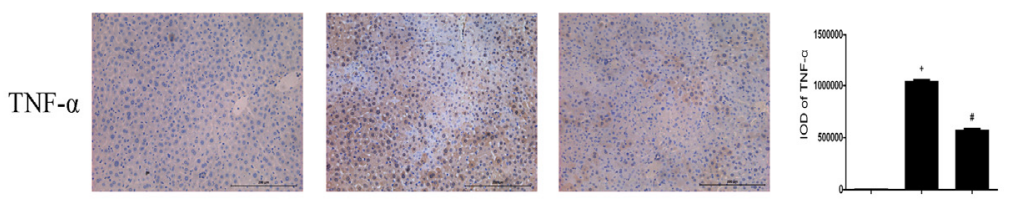

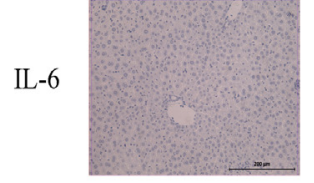

Sham

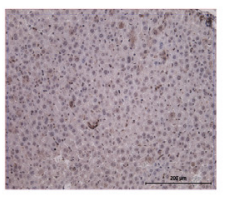

IR

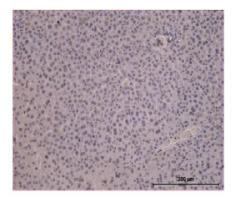

$\operatorname{ASX}(60 \mathrm{mg} / \mathrm{kg})$



Figure 3. ASX reduced the release of TNF- $\alpha$ and IL-6. (A) The level plasma of TNF- $\alpha$ and IL-6 is shown as the mean \pm SD of 6 mice per group. ${ }^{*} p<0.05$ for IR $v s$. Sham, ${ }^{\#} p<0.05$ for ASX (60 mg/kg) vs. IR; (B) The mRNA expression of TNF- $\alpha$ and IL- 6 was assessed by real-time PCR. The experiments were repeated three times and the data are shown as the mean \pm SD. ${ }^{*} p<0.05$ for IR vs. Sham, ${ }^{*} p<0.05$ for ASX $(60 \mathrm{mg} / \mathrm{kg}) v s$. IR; (C) Western blots of the expression of TNF- $\alpha$ and IL- 6 are shown by gray bands at each time point; (D) Representative immunohistochemistry staining shows the expression of TNF- $\alpha$ and IL-6 at 8 h. ${ }^{*} p<0.05$ for IR vs. Sham, ${ }^{*} p<0.05$ for ASX $(60 \mathrm{mg} / \mathrm{kg}) v s$. IR. Original magnifications: $200 \times$. 
A
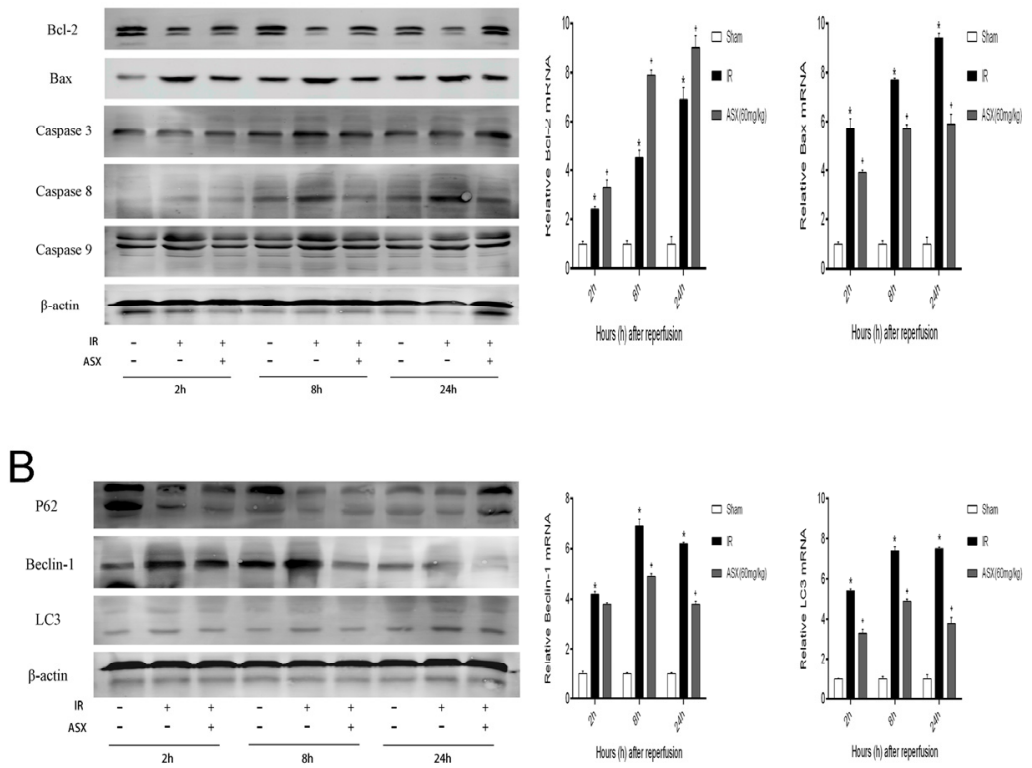

C
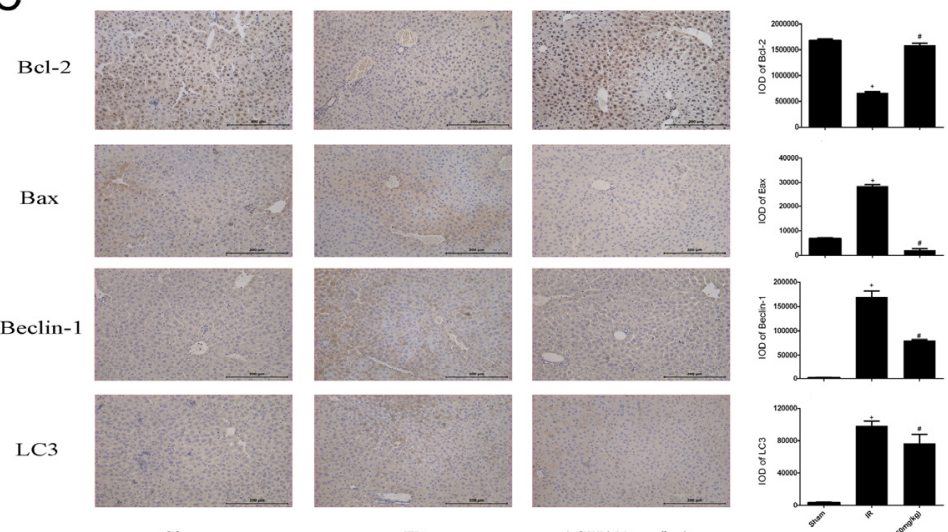

D



Sham

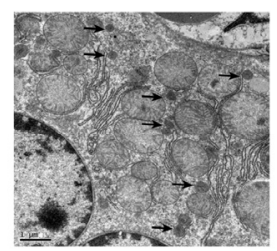

IR

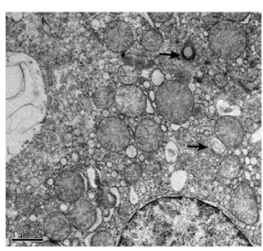

$\operatorname{ASX}(60 \mathrm{mg} / \mathrm{kg})$

Figure 4. ASX reduced the proteins related to apoptosis and autophagy. (A) Protein expression of Bcl-2, Bax, Caspase-3, Caspase- 8 and Caspase- 9 was detected by western blots. The mRNA expression of Bcl-2 and Bax was detected by real-time PCR, and described as the mean $\pm \mathrm{SD} .{ }^{*} p<0.05$ for IR $v s$. Sham, ${ }^{+} p<0.05$ for ASX $(60 \mathrm{mg} / \mathrm{kg}) v s$. IR; (B) Western blots of P62, Beclin-1 and LC3 are shown by gray bands. The gene expression of Beclin-1 and LC3 were determined by real-time PCR. Data are described as the mean \pm SD. ${ }^{*} p<0.05$ for IR $v s$. Sham, ${ }^{+} p<0.05$ for ASX $(60 \mathrm{mg} / \mathrm{kg}) v s$. IR; (C) Representative immunohistochemistry staining shows the expression of Bcl-2, Bax, Caspase-9, Beclin-1 and LC3 at 8 h. ${ }^{*} p<0.05$ for IR $v s$. Sham, ${ }^{*} p<0.05$ for ASX $(60 \mathrm{mg} / \mathrm{kg}) v s$. IR. Original magnifications: $200 \times$; (D) Arrows indicate autophagosomes detected in liver tissue by transmission electron microscopy. Original magnifications: $10,000 \times$. 
A

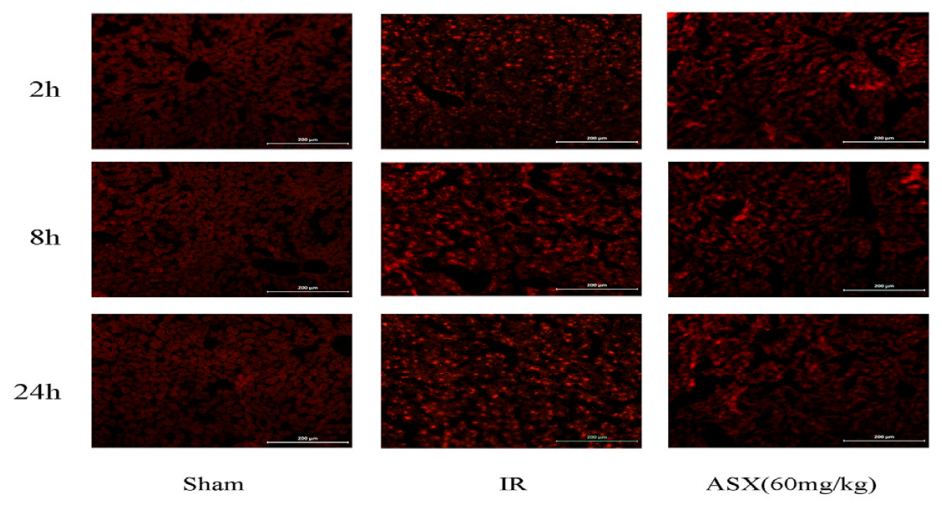

B

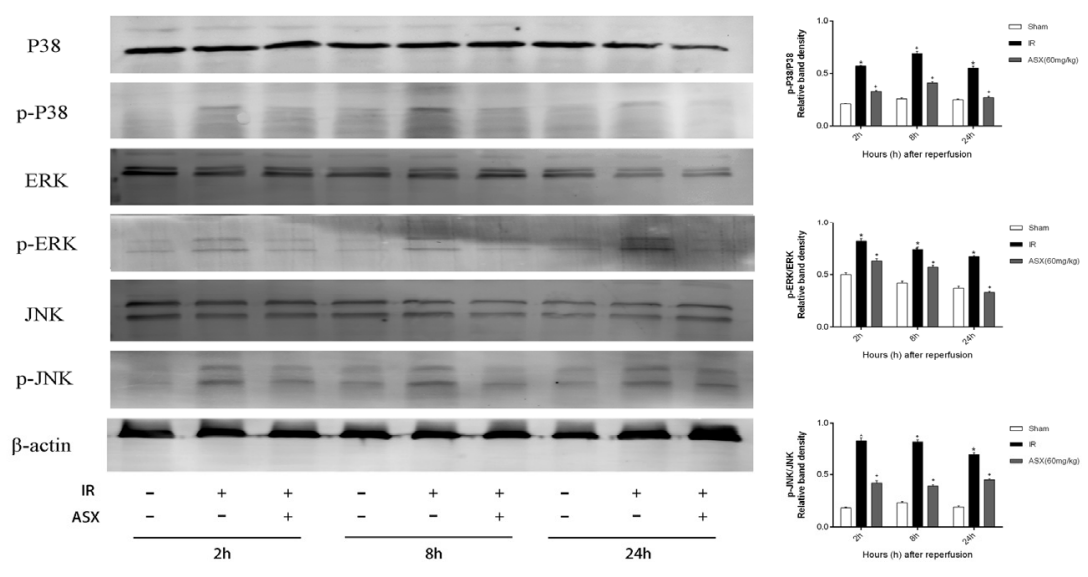

C

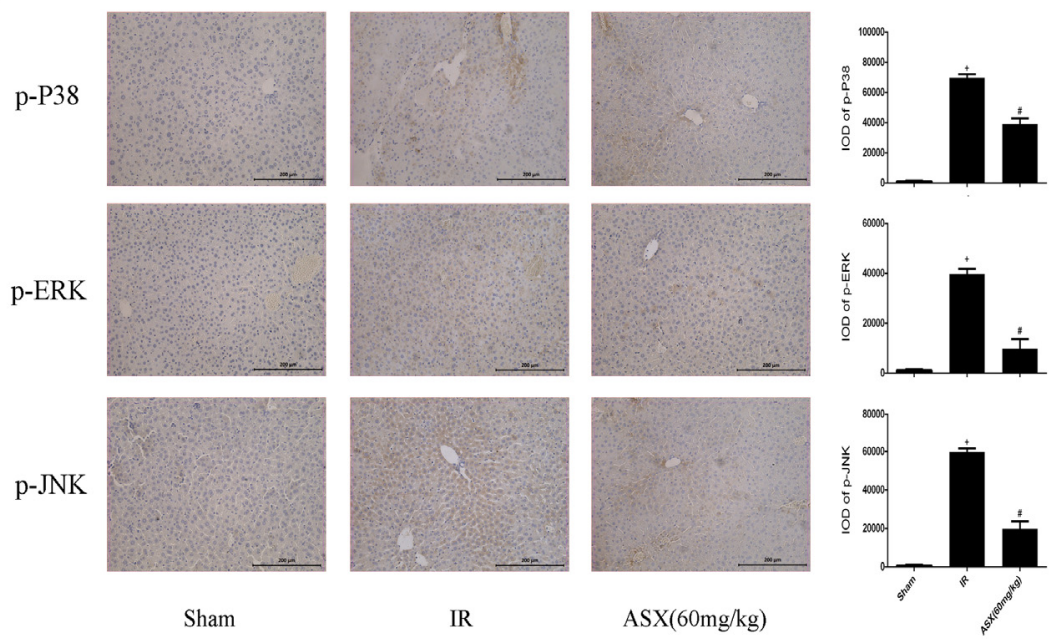

Figure 5. ASX inhibited ROS generation and the phosphorylation of proteins in the MAPK family. (A) The production of ROS was detected by the fluorescent probe, DHE. Bright red dot-like substances indicate strong ROS expression. Original magnification: $200 \times$; (B) Protein expression of P38 MAPK, p-P38 MAPK, ERK, p-ERK, JNK, p-JNK was detected by western blots. The quantitative evaluation was determined by relative band density of phosphorylation levels. ${ }^{*} p<0.05$ for IR $v s$. Sham, ${ }^{+} p<0.05$ for ASX (60 mg/kg) vs. IR; (C) Representative immunohistochemistry staining shows the expression of p-P38 MAPK, p-ERK and p-JNK at 8 h. ${ }^{*} p<0.05$ for IR vs. Sham, ${ }^{*} p<0.05$ for ASX $(60 \mathrm{mg} / \mathrm{kg}) v s$. IR. Original magnification: $200 \times$. 


\subsection{ASX Attenuates ROS/MAPK Signal Pathways by Inhibiting the Phosphorylation of P38 MAPK,} ERK and JNK

Mitogen-activated protein kinase (MAPK) is expressed in all eukaryotic cells including P38 MAPK, ERK and JNK subgroups that control cell growth, differentiation, apoptosis and stress reactions to the environment [13]. The production of reactive oxygen species (ROS) after IR injury and the oxidative stress reaction are essential for apoptosis. We used the fluorescent probe, DHE, histochemical staining, and western blot to detect ROS and proteins related to the MAPK family. As shown in Figure 5A, ROS were dyed bright red by DHE compared with the sham group and showed strong expression in the IR group. After ASX treatment, reductions in bright red dot-like substances indicated less ROS production. In addition, P38 MAPK, ERK, JNK and their phosphorylation levels were measured to calculate the proportion of protein phosphorylation (Figure 5B). The results showed that the phosphorylation level significantly increased after IR, which was consistent with the expression of ROS. Following ASX administration, a downward trend in p-P38 MAPK, p-ERK and p-JNK expression in liver tissue was observed, which was consistent with immunohistochemical staining (Figure 5C). These results suggested that ASX inhibited ROS generation and the phosphorylation of key proteins related to the MAPK family, which may be an essential pathway in mitigating cell apoptosis and autophagy.

\section{Discussion}

The mechanism of hepatic IR has not been clarified due to its complexity, but increasing evidence shows that the production of ROS and inflammatory cytokines are key factors in inducing liver damage [40]. ASX, a natural antioxidant from marine organisms, may improve the outcome of liver transplantation.

We demonstrated that ASX and its solvent had no negative effects on liver function and pathology in normal liver tissue. Thus, the effect of ASX on ROS and cytokines induced by hepatic IR injury requires further investigation. The sharp rise in ALT and AST is an important manifestation of our successful IR model. Serum levels of liver enzymes declined significantly, which was consistent with structural disorders, and HE staining showed the presence of necrosis. We selected an ASX dose of $60 \mathrm{mg} / \mathrm{kg}$ to assess TNF- $\alpha$ and IL- 6 which mediate cell apoptosis and necrosis at the gene and protein levels. ASX inhibited both TNF- $\alpha$ and IL-6, which has been described by previous researchers. Kupffer cells, known as hepatic macrophages, are activated by IR to produce ROS, TNF- $\alpha$, IL- 6 and other highly reactive molecules that stimulate $\mathrm{T}$ and $\mathrm{B}$ cells and mediate the adhesion of white blood cells, platelets and liver sinusoidal endothelial cells, causing aggravation of the hepatic microcirculation $[41,42]$. In addition, the activation of NF- $\kappa$ B by TNF- $\alpha$ also increased inflammation leading to injury [43]. These effects resulted in ALT and AST being released from ruptured cell cytoplasm, and their plasma levels corresponded with the extent of cellular damage [44]. ASX can scavenge radicals at the outer and inner parts of the cell membrane, due to its unique molecular structure with hydroxyl and keto moieties on each ionone ring $[45,46]$. ASX provides protection by reducing oxygen free radicals and pro-inflammatory factors. However, the pathways which play a role in ASX hepatocyte protection by avoiding oxidative stress have not yet been clarified.

Mitogen-activated protein kinase (MAPK), originally purified from fat cells by Ray and Sturgill in 1988, has been described as four distinct subgroups: P38 MAPK, extracellular signal-regulated kinase 
(ERK), c-jun $N$-terminal kinase (JNK) and big MAPK 1 (BMK1) [47,48]. The first three subgroups are usually activated concurrently in animals. In resting cells, the MAPK family, distributed in the cytoplasm, is activated by phosphorylation or inactivated by MAPK phosphatases (MKPs), a class of dual-specificity phosphatases (DSPs) as negative regulators in MAPK pathway, in order to migrate to the nucleus and cell membrane, resulting in the regulation of gene transcription $[49,50]$. P38 MAPK is an important component of the MAPK family which can be activated by extracellular stress, including oxidative stress, pro-inflammatory cytokines, ultraviolet radiation, and heat shock [14,51-53]. P38 activation also stimulates monocyte-macrophages to produce TNF- $\alpha$, IL- 6 as well as increased nitric oxide (NO) accelerated ROS. Inhibition of P38 has a significant protective effect on multiple systems. Kim et al. showed that ASX inhibited apoptotic cell death in neural progenitor cells via modulation of the P38 and MEK signaling pathways [51]. Systemic inhibition of P38 MAPK weakened ongoing pulmonary inflammation, as described by Nick and colleagues [53]. Another effective advantage of MAPK inhibition has been shown in type II diabetes, Crohn's disease, acute colitis and other systems [52,54,55]. In hepatic IR injury, P38 MAPK in addition to ERK and JNK participates in the injury induced by ROS and cytokines. Koike and Hashimoto reduced IR injury following heart, lung and liver transplantations by adding P38 MAPK inhibitors [56,57]. In our study, we also conducted comprehensive examinations of mRNA and protein levels. The results showed that activated phosphorylated P38 MAPK (p-P38 MAPK) increased due to ROS and cytokines caused by IR, and its phosphorylation reduced after ASX treatment. This shows that ASX inhibited the P38 MAPK pathway by reducing ROS and TNF- $\alpha$. Activation levels of ERK and JNK have also been consistently validated in previous studies $[13,14,58-60]$. We consider that ASX weakened phosphorylation of the MAPK family and provided protection by scavenging ROS and inactivating Kupffer cells which release inflammatory factors.

How does inhibition of P38 MAPK protect the liver from damage? Studies have found that P38 not only enhanced cleaved caspase- 8 mediated apoptosis induced by TNF- $\alpha$, but also had an effect on the Bcl-2 family resulting in increased intrinsic apoptosis [47]. The release of ROS and cytokines hindered mitochondrial energy metabolism, and stimulated related enzymes that could phosphorylate P38 MAPK. Phosphorylated P38 MAPK transferred Bax located in the cytoplasm of normal hepatocytes to mitochondria, forming dimers that had a direct influence on the membrane permeability transition pore (MPTP) [61,62]. Open MPTPs triggered mitochondrial permeability transition (MPT) to release cytochrome $\mathrm{C}$ and then activate caspase-9 resulting in apoptosis. ERK and JNK pathways activated by TNF- $\alpha$ and IL-6 can phosphorylate Bcl-2 (inactive form) to prevent inhibition of cell apoptosis $[63,64]$. These three pathways eventually interact with each other to activate cleaved caspase-3, leading to liver cell apoptosis [65]. The effect of ASX on the elimination of ROS and TNF- $\alpha$ was evaluated by PCR, western blot and immunohistochemistry staining. The key proteins in the MAPK family, such as P38, ERK, JNK, Bcl-2, Bax, and Caspases, were determined and their expression levels assessed. In addition, autophagy was found to be involved in hepatic IR injury. A reduction in related oxidative stress factors decreased the activity of Bax in mitochondrial transfer, which mediated free active Bcl-2. Bcl-2 containing Bcl-2 homology 3 (BH3)-only domains can be combined with Beclin-1 to inhibit autophagy [66]. Inhibition of autophagy limited the conversion of LC3-I to LC3-II and the formation of autophagosomes and P62, and the autophagy-related transporter combined with mature LC3 via its special ubiquitin-binding domains was detected, as shown in Figure 6 [67]. Thus, we observed increased Beclin-1 and LC3 and reduced P62 in the ASX-treated group. 


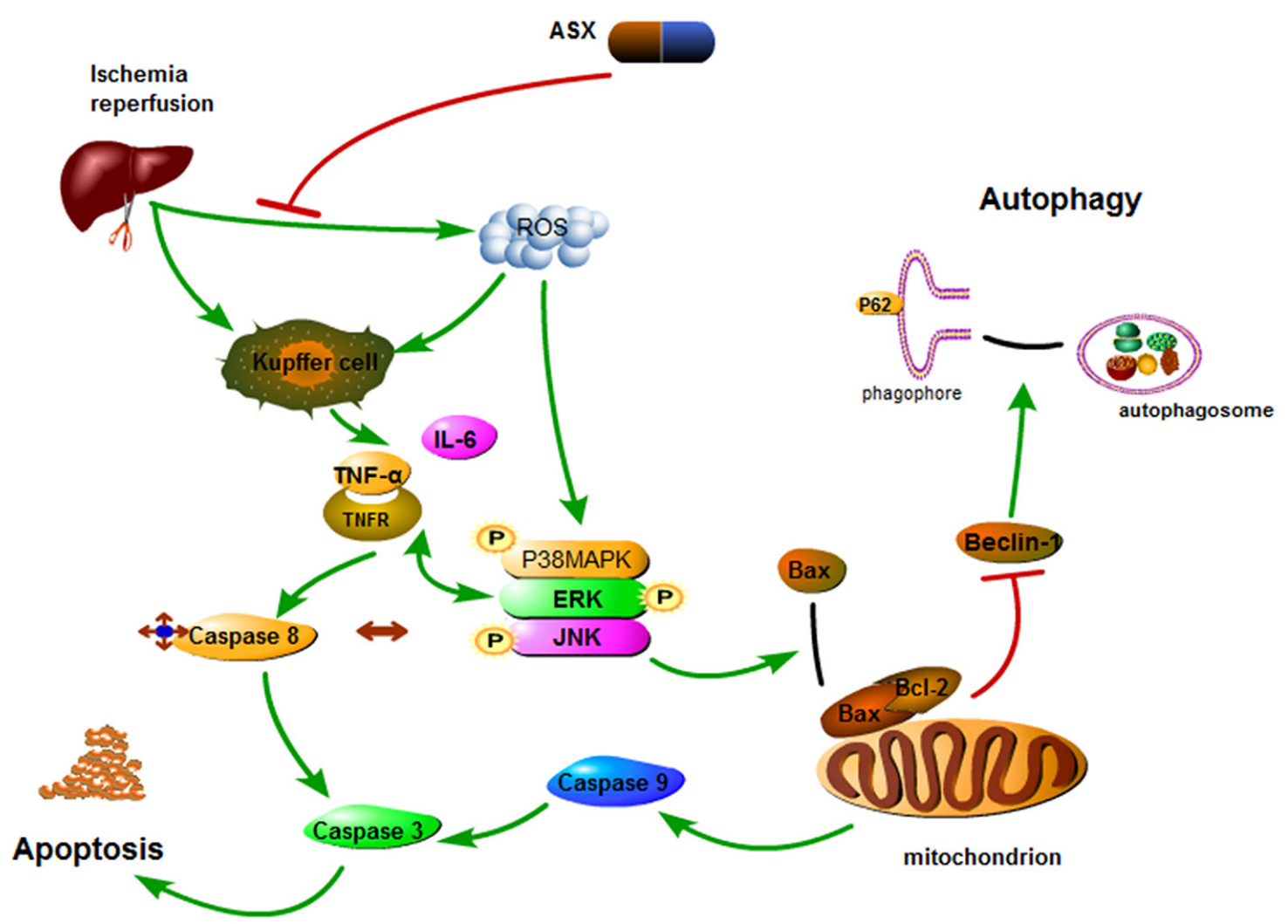

Figure 6. Mechanism of action of astaxanthin. In hepatic IR, astaxanthin weakened phosphorylation of the MAPK family and provided protection by scavenging ROS and inactivating Kupffer cells which release inflammatory factors. MAPK pathways activated by TNF- $\alpha$ and IL- 6 can not only activate capase- 8 but also phosphorylate Bcl- 2 to induce caspase- 9 activation. Inactive Bcl-2 released Beclin-1 that enhanced autophagy. Thus, astaxanthin inhibits the release of ROS and cytokines during hepatic IR to offer protection by inhibiting apoptosis and autophagy.

In summary, we preliminarily found that activation of the MAPK family mediated by ROS and cytokines which induced apoptosis and autophagy could be inhibited by ASX during hepatic IR injury in mice. The link between related drugs and pathways requires further investigation in order to identify safer and effective therapies for hepatic IR injury due to its complex mechanism.

\section{Experimental Section}

\subsection{Animals}

All experimental protocols carried out on mice were approved by the Animal Care and Use Committee at Shanghai Tongji University. Male Balb/C mice weighing 20-25 g (6-8 weeks old) were housed in a clean room at a constant temperature $\left(22-25^{\circ} \mathrm{C}\right)$ and a $12 \mathrm{~h}: 12 \mathrm{~h}$ light-dark cycle. The mice were purchased from Shanghai SLAC Laboratory Animal Co. Ltd. (Shanghai, China) and given food and water ad libitum. The study was performed in accordance with the standards established by the recommendations of the Guide for the National Science Council of the Republic of China. 


\subsection{Preparation of Reagents}

ASX was purchased from Sigma-Aldrich (St. Louis, MO, USA) and stored in the dark at $-20{ }^{\circ} \mathrm{C}$. The antibodies used in this study included those against Bcl-2, Bax, Caspase-3, Caspase-8, Caspase-9, LM3, TNF- $\alpha$, IL-6, p-JNK (all from Cell Signaling Technology, Danvers, MA, USA), P62, Beclin1, JNK, P38 MAPK, p-P38 MAPK, $\beta$-actin (all purchased from Proteintech, Chicago, IL, USA), ERK, and p-ERK (both from Epitomics, Burlingame, CA, USA). ROS Fluorescent Probe-DHE was purchased from Vigorous (Beijing, China). TNF- $\alpha$ and IL-6 Enzyme Linked Immunosorbent Assay (ELISA) kits were acquired from eBioscience (San Diego, CA, USA).

\subsection{Experimental Design}

The mice were randomly distributed to one of six groups as follows:

Group I, control group $(n=8)$ : mice received saline by gavage

Group II, oil group $(n=8)$ : mice received olive oil by gavage

Group III, ASX group $(n=16)$ : mice received ASX $(30 \mathrm{mg} / \mathrm{kg}$ or $60 \mathrm{mg} / \mathrm{kg})$ by gavage

Group IV, sham group $(n=18)$ : mice received olive oil by gavage without IR

Group V, IR group $(n=18)$ : mice received olive oil by gavage before IR

Group VI, IR + ASX group ( $n=36)$ : mice received ASX $(30 \mathrm{mg} / \mathrm{kg}$ or $60 \mathrm{mg} / \mathrm{kg})$ by gavage before IR

ASX was dissolved in olive oil to obtain a suspension and stored in the dark at $4{ }^{\circ} \mathrm{C}$. The mice were given saline, olive oil or ASX for 14 consecutive days. All mice in Group I, II, III and IV were killed after 14 days, while, six mice were randomly selected from Group IV, V and VI (6 mice in each dose) were sacrificed at $2 \mathrm{~h}, 8 \mathrm{~h}$ or $24 \mathrm{~h}$ after IR. Serum and liver tissues were obtained for further experiments.

\subsection{Mouse Model of Hepatic Ischemia-Reperfusion Injury}

A mouse model of 70\% hepatic warm ischemia was established according to a previously reported method [68]. Mice were fasted for $24 \mathrm{~h}$ before surgery, but allowed water. The mice were anesthetized by an intraperitoneal standard dosage (1.25\%) of sodium pentobarbital (Nembutal, St. Louis, MO, USA). The abdominal viscera were identified after entering the intra-abdominal cavity along the medioventral line. The middle and left hepatic lobes, and then, the first porta hepatis were dissociated from adjacent structures using wet cotton swabs. Hepatic ischemia was achieved by occluding the hepatic artery, portal vein and bile duct using vascular clamps to obtain $70 \%$ tissue ischemia. When the hepatic lobe showed a color change from crimson to light red, the incision was covered with humid saline gauze for $60 \mathrm{~min}$. The abdominal incision was then sewn without vascular clamps. To maintain a constant body temperature, we applied an animal body temperature maintenance instrument (ZS Dichuang, Beijing, China).

\subsection{ALT and AST Enzyme-Activity and Cytokine Measurements}

Sera were isolated by centrifuging at $4500 \times g$ for $10 \mathrm{~min}$ after storing for $4-5 \mathrm{~h}$ at $4{ }^{\circ} \mathrm{C}$. Fifty microliters aliquots of serum were placed in Eppendorf (EP) tubes and stored at $-80^{\circ} \mathrm{C}$. Serum ALT and AST were measured by an automated chemical analyzer (Olympus AU1000, Tokyo, Japan). The plasma levels of TNF- $\alpha$ and IL- 6 were assessed using ELISA kits, according to the manufacturer's protocol. 


\subsection{Histopathological Evaluation}

The removed liver tissue was fixed with $4 \%$ paraformaldehyde for at least $24 \mathrm{~h}$, and then dehydrated using different concentrations of ethanol. After immersion in xylene, the samples were waxed in paraffin blocks to prevent crystallization. Sections $5 \mu \mathrm{m}$ thick were cut and stored at room temperature. The sections were stained with hematoxylin-eosin (HE) for observation under a light microscope.

\subsection{Western Blot Analysis}

Fresh liver tissues were cut into pieces and immediately stored in liquid nitrogen. Tissue blocks of approximately $100 \mathrm{mg}$ were disintegrated by radioimmunoprecipitation assay (RIPA) lysis buffer containing protease inhibitors (PI) and phenylmethane-sulfonyl fluoride (PMSF). The extracted protein was mixed with loading buffer after bicinchoninic acid (BCA) quantification and stored at $-20{ }^{\circ} \mathrm{C}$. According to the standard curve, the same amount of protein was added to sodium dodecyl sulfate (SDS)-polyacrylamide gels $(8 \%-12.5 \%)$ for gel electrophoresis, and then transferred onto $0.22 \mu \mathrm{m}$ polyvinylidene fluoride (PVDF) membranes. Bovine serum albumin (BSA, 5\%) was used to close all nonspecific sites of the membranes at least $1 \mathrm{~h}$ before dilute primary antibodies (Bcl-2, 1:500; Bax, 1:500; Caspase-3, 1:500; Caspase-8, 1:1000; Caspase-9, 1:500; IL-6, 1:500; TNF- $\alpha, 1: 500 ;$ LC3, 1:1000; Beclin-1, 1:500; JNK, 1:1000; p-JNK, 1:500; p-ERK, 1:1000; ERK, 1:500; p-P38, 1:500; P-38, 1:1000 and $\beta$-actin, 1:1000) were combined with the proteins at $4{ }^{\circ} \mathrm{C}$. The next day, phosphate buffer solution containing $0.1 \%$ Tween 20 (PBST) was used to wash the membranes three times before and after incubation with the secondary antibodies (horseradish peroxidase-conjugated anti-rabbit or anti-mouse $\mathrm{IgG}$ ) in the proportion of 1:2000 for $1 \mathrm{~h}$ at $37^{\circ} \mathrm{C}$. The strength of the protein signals was detected using the Odyssey two-color infrared laser imaging system (LI-COR Biosciences, Lincoln, NE, USA).

\subsection{Immunohistochemical Staining}

The slices were dried in a drying oven for $2 \mathrm{~h}$ and then immersed in dimethyl benzene for dewaxing. Different concentrations of ethanol were used to dehydrate the prepared sections. After washing with phosphate buffer solution (PBS) three times, antigen retrieval was then performed with citrate buffer by heating to $95^{\circ} \mathrm{C}$ for $10 \mathrm{~min}$ and cooling to room temperature (four cycles). In order to inhibit endogenous peroxidase activity, we added $3 \%$ hydrogen peroxide to the sections at room temperature for 20 min and then blocked them with 5\% BSA solution. The liver slices were then incubated with antibodies directed against Bcl-2 (1:100), Bax (1:500), Beclin-1 (1:100), LC3 (1:500), p-JNK (1:50), p-ERK (1:100), p-P38 MAPK (1:50) for $24 \mathrm{~h}$ at $4{ }^{\circ} \mathrm{C}$ and with a secondary antibody (1:50) for $1 \mathrm{~h}$ at $37{ }^{\circ} \mathrm{C}$ after washing. A diaminobenzidine (DAB) kit was used to show granular brown substances which were observed and captured by a microscope with a digital camera (Leica Wetzlar, Germany). Image Pro Plus Software 6.0 (Media Cybernetics, Silver Spring, MD, USA) was used to calculate the integrated optical densities (IOD) of the sections.

\subsection{SYBR Green Real-Time Polymerase Chain Reaction (PCR)}

Approximately $100 \mathrm{mg}$ of tissue were removed from liquid nitrogen and triturated in mortars soaked with diethyl pyrocarbonate (DEPC) treated water. Trizol, chloroform and isopropyl alcohol were added 
to the tissues for extraction of total RNA. After determination of the purity and concentration, a reverse transcription kit (TaKaRa Biotechnology, Dalian, China) was used to transcribe RNA into cDNA. We used a $10 \mu \mathrm{L}$ reaction volume containing primers and related enzymes for SYBR Green quantitative real-time PCR using a 7900HT fast real-time PCR system (Applied Biosystems, NewYork, NY, USA), according to the Premix EX Taq protocols (TaKaRa Biotechnology, Dalian, China). Gene expression was calculated on the basis of the solubility curve and the ratios of target genes. All primers used in the experiments are shown in Table 1.

Table 1. Nucleotide sequences of primers used for qRT-PCR.

\begin{tabular}{|c|c|c|}
\hline Gene & & Primer Sequence $\left(5^{\prime}-3^{\prime}\right)$ \\
\hline \multirow{2}{*}{$T N F-\alpha$} & & CAGGCGGTGCCTATGTCTC \\
\hline & Reverse & CGATCACCCCGAAGTTCAGTAG \\
\hline \multirow{2}{*}{$I L-6$} & Forward & CTGCAAGAGACTTCCATCCAG \\
\hline & Reverse & AGTGGTATAGACAGGTCTGTTGG \\
\hline \multirow{2}{*}{$L C 3$} & Forward & GACCGCTGTAAGGAGGTGC \\
\hline & Reverse & AGAAGCCGAAGGTTTCTTGGG \\
\hline \multirow{2}{*}{ Beclin1 } & Forward & ATGGAGGGGTCTAAGGCGTC \\
\hline & Reverse & TGGGCTGTGGTAAGTAATGGA \\
\hline \multirow{2}{*}{ Bax } & Forward & AGACAGGGGCCTTTTTGCTAC \\
\hline & Reverse & AATTCGCCGGAGACACTCG \\
\hline \multirow{2}{*}{ Bcl-2 } & Forward & GCTACCGTCGTCGTGACTTCGC \\
\hline & Reverse & CCCCACCGAACTCAAAGAAGG \\
\hline \multirow{2}{*}{$\beta$-actin } & Forward & GGCTGTATTCCCCTCCATCG \\
\hline & Reverse & CCAGTTGGTAACAATGCCATGT \\
\hline
\end{tabular}

\subsection{Transmission Electron Microscopy}

Liver tissues were prefixed by immersion in $3 \%$ glutaraldehyde and $0.2 \%$ mol/L sodium cacodylate for $4 \mathrm{~h}$ and fixed in $1 \%$ osmium tetroxide for $1 \mathrm{~h}$. Autophagosomes were observed by transmission electron microscopy (LEO 906E, Oberkochen, Germany).

\subsection{Reactive Oxygen Species (ROS) of Liver Tissue Assay}

The ROS fluorescent probe, dihydroethidium (DHE), can penetrate the cell membrane and is oxidized by ROS to produce a red fluorescence. Fresh liver tissues were fixed with $4 \%$ formaldehyde and then dehydrated using $30 \%$ sucrose solution overnight at $4{ }^{\circ} \mathrm{C}$. The tissues were embedded using opti-mum cutting temperature compound (OCT) and cut into sections $5 \mu \mathrm{m}$ thick. After adequate washing, the sections were incubated with DHE $(10 \mu \mathrm{M})$ for $60 \mathrm{~min}$ in the dark. The sections were then washed with PBS three times, for $10 \mathrm{~min}$ each time. Red light stimulated by green light was acquired by the fluorescence microscope for calculation of the red area.

\subsection{Statistical Analysis}

All data are presented as the mean \pm standard deviation (SD) and analyzed using SPSS 20.0 software (Chicago, IL, USA). Differences among groups were detected by one-way analysis of variance (ANOVA) using the Student-Newman-Keuls (SNK) method. $p<0.05$ was considered statistically significant. 


\section{Conclusions}

Pretreatment with astaxanthin attenuated hepatic ischemia reperfusion-induced apoptosis and autophagy via the ROS/MAPK pathway in mice, and the relationship between the two may be associated with the reduction of inflammatory cytokines.

\section{Acknowledgments}

The research was financially supported by National Natural Science Foundation of China (grant No. 81270515).

\section{Author Contributions}

Chuanyong Guo, Yingqun Zhou and Jingjing Li conceived and designed the experiments; Jingjing Li, Jianrong Wang and Yuqing Zhou performed the experiments; Fan Wang, Yujing Xia, Kan Chen, Qin Yin and Jie Lu analyzed the data; Weiqi Dai, Sainan Li, Tong Liu, Yuanyuan Zheng and Wenxia Lu contributed the reagents and materials; Jingjing Li wrote the manuscript.

\section{Conflicts of Interest}

The authors declare no conflict of interest.

\section{References}

1. Li, Y.; Yang, Y.; Feng, Y.; Yan, J.; Fan, C.; Jiang, S.; Qu, Y. A review of melatonin in hepatic ischemia/reperfusion injury and clinical liver disease. Ann. Med. 2014, 46, 503-511.

2. Bhogal, R.H.; Sutaria, R.; Afford, S.C. Hepatic liver ischemia/reperfusion injury: Processes in inflammatory networks-A review. Liver Transpl. 2011, 17, 95-96.

3. Jennings, R.B.; Sommers, H.M.; Smyth, G.A.; Flack, H.A.; Linn, H. Myocardial necrosis induced by temporary occlusion of a coronary artery in the dog. Arch. Pathol. 1960, 70, 68-78.

4. Guan, L. Mechanisms of hepatic ischemia-reperfusion injury and protective effects of nitric oxide. World J. Gastrointest. Surg. 2014, 6, 122-128.

5. Adam, A.N.I. Some mechanisms of the protective effect of ischemic preconditioning on rat liver ischemia-reperfusion injury. Int. J. Gen. Med. 2014, 7, 483-489.

6. Chu, M.J.; Hickey, A.J.; Phillips, A.R.; Bartlett, A.S. The impact of hepatic steatosis on hepatic ischemia-reperfusion injury in experimental studies: A systematic review. Biomed. Res. Int. 2013, 2013, doi:10.1155/2013/192029.

7. Rao, J.; Yue, S.; Fu, Y.; Zhu, J.; Wang, X.; Busuttil, R.W.; Kupiec-Weglinski, J.W.; Lu, L.; Zhai, Y. ATF6 mediates a pro-inflammatory synergy between ER stress and TLR activation in the pathogenesis of liver ischemia-reperfusion injury. Am. J. Transplant. 2014, 14, 1552-1561.

8. Park, S.W.; Kang, J.W.; Lee, S.M. Role of Kupffer cells in ischemic injury in alcoholic fatty liver. J. Surg. Res. 2015, 194, 91-100. 
9. Nace, G.W.; Huang, H.; Klune, J.R.; Eid, R.E.; Rosborough, B.R.; Korff, S.; Li, S.; Shapiro, R.A.; Stolz, D.B.; Sodhi, C.P.; et al. Cellular-specific role of toll-like receptor 4 in hepatic ischemiareperfusion injury in mice. Hepatology 2013, 58, 374-387.

10. Sanderson, T.H.; Reynolds, C.A.; Kumar, R.; Przyklenk, K.; Huttemann, M. Molecular mechanisms of ischemia-reperfusion injury in brain: Pivotal role of the mitochondrial membrane potential in reactive oxygen species generation. Mol. Neurobiol. 2013, 47, 9-23.

11. Sun, Y.; Pu, L.Y.; Lu, L.; Wang, X.H.; Zhang, F.; Rao, J.H. N-acetylcysteine attenuates reactive-oxygen-species-mediated endoplasmic reticulum stress during liver ischemia-reperfusion injury. World J. Gastroenterol. 2014, 20, 15289-15298.

12. Brass, C.A.; Roberts, T.G. Hepatic free radical production after cold storage: Kupffer cell-dependent and -independent mechanisms in rats. Gastroenterology 1995, 108, 1167-1175.

13. Schwabe, R.F.; Brenner, D.A. Mechanisms of Liver Injury. I. TNF-alpha-induced liver injury: Role of IKK, JNK, and ROS pathways. Am. J. Physiol. Gastrointest. Liver Physiol. 2006, 290, G583-G589.

14. Nakagawa, H.; Maeda, S. Molecular mechanisms of liver injury and hepatocarcinogenesis: Focusing on the role of stress-activated MAPK. Patholog. Res. Int. 2012, 2012, doi:10.1155/2012/172894.

15. Tiberio, L.; Tiberio, G.A.; Bardella, L.; Cervi, E.; Cerea, K.; Dreano, M.; Garotta, G.; Fra, A.; Montani, N.; Ferrari-Bravo, A.; et al. Mechanisms of interleukin-6 protection against ischemia-reperfusion injury in rat liver. Cytokine 2006, 34, 131-142.

16. Shen, M.; Lu, J.; Dai, W.; Wang, F.; Xu, L.; Chen, K.; He, L.; Cheng, P.; Zhang, Y.; Wang, C.; et al. Ethyl Pyruvate Ameliorates Hepatic Ischemia-Reperfusion Injury by Inhibiting Intrinsic Pathway of Apoptosis and Autophagy. Mediators Inflamm. 2013, 2013, 1-12.

17. Kohli, V.; Selzner, M.; Madden, J.F.; Bentley, R.C.; Clavien, P.A. Endothelial cell and hepatocyte deaths occur by apoptosis after ischemia-reperfusion injury in the rat liver. Transplantation 1999, 67, 1099-1105.

18. Imahashi, K.; Schneider, M.D.; Steenbergen, C.; Murphy, E. Transgenic expression of Bcl-2 modulates energy metabolism, prevents cytosolic acidification during ischemia, and reduces ischemia/reperfusion injury. Circ. Res. 2004, 95, 734-741.

19. Selzner, M.; Rudiger, H.A.; Selzner, N.; Thomas, D.W.; Sindram, D.; Clavien, P.A. Transgenic mice overexpressing human Bcl-2 are resistant to hepatic ischemia and reperfusion. J. Hepatol. 2002, 36, $218-225$.

20. Nikoletopoulou, V.; Markaki, M.; Palikaras, K.; Tavernarakis, N. Crosstalk between apoptosis, necrosis and autophagy. Biochim. Biophys. Acta 2013, 1833, 3448-3459.

21. Sybers, H.D.; Ingwall, J.; DeLuca, M. Autophagy in cardiac myocytes. Recent Adv. Stud. Cardiac. Struct. Metab. 1976, 12, 453-463.

22. Decker, R.S.; Wildenthal, K. Lysosomal alterations in hypoxic and reoxygenated hearts. I. Ultrastructural and cytochemical changes. Am. J. Pathol. 1980, 98, 425-444.

23. Liang, X.H.; Kleeman, L.K.; Jiang, H.H.; Gordon, G.; Goldman, J.E.; Berry, G.; Herman, B.; Levine, B. Protection against fatal Sindbis virus encephalitis by beclin, a novel Bcl-2-interacting protein. J. Virol. 1998, 72, 8586-8596.

24. Naguib, Y.M. Antioxidant activities of astaxanthin and related carotenoids. J. Agric. Food Chem. 2000, 48, 1150-1154. 
25. Shen, M.; Chen, K.; Lu, J.; Cheng, P.; Xu, L.; Dai, W.; Wang, F.; He, L.; Zhang, Y.; Chengfen, W.; et al. Protective Effect of Astaxanthin on Liver Fibrosis through Modulation of TGF-1 Expression and Autophagy. Mediators Inflamm. 2014, 2014, 1-14.

26. Ambati, R.; Moi, P.; Ravi, S.; Aswathanarayana, R. Astaxanthin: Sources, extraction, stability, biological activities and its commercial applications-A review. Mar. Drugs 2014, 12, 128-152.

27. Li, J.; Xia, Y.; Liu, T.; Wang, J.; Dai, W.; Wang, F.; Zheng, Y.; Chen, K.; Li, S.; Abudumijiti, H.; et al. Protective effects of astaxanthin on ConA-induced autoimmune hepatitis by the $\mathrm{JNK} / \mathrm{p}-\mathrm{JNK}$ pathway-mediated inhibition of autophagy and apoptosis. PLOS ONE 2015, 10, e120440.

28. Kamath, B.S.; Srikanta, B.M.; Dharmesh, S.M.; Sarada, R.; Ravishankar, G.A. Ulcer preventive and antioxidative properties of astaxanthin from Haematococcus pluvialis. Eur. J. Pharmacol. 2008, 590, 387-395.

29. Yang, Y.; Kim, B.; Park, Y.K.; Koo, S.I.; Lee, J.Y. Astaxanthin prevents TGF $\beta 1$-induced pro-fibrogenic gene expression by inhibiting Smad3 activation in hepatic stellate cells. Biochim. Biophys. Acta 2015, 1850, 178-185.

30. Song, X.; Wang, B.; Lin, S.; Jing, L.; Mao, C.; Xu, P.; Lv, C.; Liu, W.; Zuo, J. Astaxanthin inhibits apoptosis in alveolar epithelial cells type II in vivo and in vitro through the ROS-dependent mitochondrial signalling pathway. J. Cell. Mol. Med. 2014, 18, 2198-2212.

31. Franceschelli, S.; Pesce, M.; Ferrone, A.; de Lutiis, M.A.; Patruno, A.; Grilli, A.; Felaco, M.; Speranza, L. Astaxanthin treatment confers protection against oxidative stress in U937 cells stimulated with lipopolysaccharide reducing $\mathrm{O}_{2}$-production. PLOS ONE 2014, 9, e88359.

32. Terazawa, S.; Nakajima, H.; Shingo, M.; Niwano, T.; Imokawa, G. Astaxanthin attenuates the UVB-induced secretion of prostaglandin E2 and interleukin-8 in human keratinocytes by interrupting MSK1 phosphorylation in a ROS depletion-independent manner. Exp. Dermatol. 2012, 21, 11-17.

33. Guerra, B.A.; Otton, R. Impact of the carotenoid astaxanthin on phagocytic capacity and ROS/RNS production of human neutrophils treated with free fatty acids and high glucose. Int. Immunopharmacol. 2011, 11, 2220-2226.

34. Marin, D.P.; Bolin, A.P.; Macedo, R.C.; Sampaio, S.C.; Otton, R. ROS production in neutrophils from alloxan-induced diabetic rats treated in vivo with astaxanthin. Int. Immunopharmacol. 2011, $11,103-109$.

35. Lu, Y.P.; Liu, S.Y.; Sun, H.; Wu, X.M.; Li, J.J.; Zhu, L. Neuroprotective effect of astaxanthin on $\mathrm{H}_{2} \mathrm{O}_{2}$-Induced neurotoxicity in vitro and on focal cerebral ischemia in vivo. Brain Res. 2010, 1360, 40-48.

36. Shen, H.; Kuo, C.C.; Chou, J.; Delvolve, A.; Jackson, S.N.; Post, J.; Woods, A.S.; Hoffer, B.J.; Wang, Y.; Harvey, B.K. Astaxanthin reduces ischemic brain injury in adult rats. FASEB J. 2009, 23, 1958-1968.

37. Lauver, D.A.; Lockwood, S.F.; Lucchesi, B.R. Disodium Disuccinate Astaxanthin (Cardax) attenuates complement activation and reduces myocardial injury following ischemia/reperfusion. J. Pharmacol. Exp. Ther. 2005, 314, 686-692.

38. Curek, G.D.; Cort, A.; Yucel, G.; Demir, N.; Ozturk, S.; Elpek, G.O.; Savas, B.; Aslan, M. Effect of astaxanthin on hepatocellular injury following ischemia/reperfusion. Toxicology 2010, 267, 147-153.

39. Sun, P.P.; Yuan, F.; Xu, J.; Sai, K.; Chen, J.; Guan, S. Cryptotanshinone ameliorates hepatic normothermic ischemia and reperfusion injury in rats by anti-mitochondrial apoptosis. Biol. Pharm. Bull. 2014, 37, 1758-1765. 
40. Zhou, G.; Dada, L.A.; Wu, M.; Kelly, A.; Trejo, H.; Zhou, Q.; Varga, J.; Sznajder, J.I. Hypoxia-induced alveolar epithelial-mesenchymal transition requires mitochondrial ROS and hypoxia-inducible factor 1. Am. J. Physiol. Lung Cell. Mol. Physiol. 2009, 297, L1120-L1130.

41. Boury, N.M.; Czuprynski, C.J. Listeria monocytogenes infection increases neutrophil adhesion and damage to a murine hepatocyte cell line in vitro. Immunol. Lett. 1995, 46, 111-116.

42. Gujral, J.S.; Bucci, T.J.; Farhood, A.; Jaeschke, H. Mechanism of cell death during warm hepatic ischemia-reperfusion in rats: Apoptosis or necrosis? Hepatology 2001, 33, 397-405.

43. Hamada, T.; Tsuchihashi, S.; Avanesyan, A.; Duarte, S.; Moore, C.; Busuttil, R.W.; Coito, A.J. Cyclooxygenase-2 deficiency enhances Th2 immune responses and impairs neutrophil recruitment in hepatic ischemia/reperfusion injury. J. Immunol. 2008, 180, 1843-1853.

44. Wang, J.; Kan, Q.; Li, J.; Zhang, X.; Qi, Y. Effect of neferine on liver ischemia-reperfusion injury in rats. Transplant. Proc. 2011, 43, 2536-2539.

45. Hussein, G.; Sankawa, U.; Goto, H.; Matsumoto, K.; Watanabe, H. Astaxanthin, a carotenoid with potential in human health and nutrition. J. Nat. Prod. 2006, 69, 443-449.

46. Goto, S.; Kogure, K.; Abe, K.; Kimata, Y.; Kitahama, K.; Yamashita, E.; Terada, H. Efficient radical trapping at the surface and inside the phospholipid membrane is responsible for highly potent antiperoxidative activity of the carotenoid astaxanthin. Biochim. Biophys. Acta 2001, 1512, 251-258.

47. Zarubin, T.; Han, J. Activation and signaling of the p38 MAP kinase pathway. Cell Res. 2005, 15, $11-18$.

48. Sturgill, T.W.; Ray, L.B. Muscle proteins related to microtubule associated protein-2 are substrates for an insulin-stimulatable kinase. Biochem. Biophys. Res. Commun. 1986, 134, 565-571.

49. Dufresne, S.D.; Bjorbaek, C.; El-Haschimi, K.; Zhao, Y.; Aschenbach, W.G.; Moller, D.E.; Goodyear, L.J. Altered extracellular signal-regulated kinase signaling and glycogen metabolism in skeletal muscle from p90 ribosomal S6 kinase 2 knockout mice. Mol. Cell. Biol. 2001, 21, 81-87.

50. Theodosiou, A.; Ashworth, A. MAP kinase phosphatases. Genome Biol. 2002, 3, doi:10.1186/ gb-2002-3-7-reviews3009.

51. Kim, J. Astaxanthin Inhibits $\mathrm{H}_{2} \mathrm{O}_{2}$-Mediated Apoptotic Cell Death in Mouse Neural Progenitor Cells via Modulation of P38 and MEK Signaling Pathways. J. Microbiol. Biotech. 2009, 19, 1355-1363

52. Sanchez-Fidalgo, S.; Villegas, I.; Rosillo, M.A.; Aparicio-Soto, M.; de la Lastra, C.A. Dietary squalene supplementation improves DSS-induced acute colitis by downregulating p38 MAPK and NFkB signaling pathways. Mol. Nutr. Food Res. 2015, 59, 284-292.

53. Nick, J.A.; Young, S.K.; Arndt, P.G.; Lieber, J.G.; Suratt, B.T.; Poch, K.R.; Avdi, N.J.; Malcolm, K.C.; Taube, C.; Henson, P.M.; et al. Selective suppression of neutrophil accumulation in ongoing pulmonary inflammation by systemic inhibition of p38 mitogen-activated protein kinase. J. Immunol. 2002, 169, 5260-5269.

54. Zhang, D.; Wang, L.; Yan, L.; Miao, X.; Gong, C.; Xiao, M.; Ni, R.; Tang, Q. Vacuolar protein sorting 4B regulates apoptosis of intestinal epithelial cells via p38 MAPK in Crohn's disease. Exp. Mol. Pathol. 2014, 98, 55-64.

55. Brown, A.E.; Palsgaard, J.; Borup, R.; Avery, P.; Gunn, D.A.; De Meyts, P.; Yeaman, S.J.; Walker, M. p38 MAPK activation upregulates proinflammatory pathways in skeletal muscle cells from insulin-resistant type 2 diabetic patients. Am. J. Physiol. Endocrinol. Metab. 2015, 308, E63-E70. 
56. Koike, N.; Takeyoshi, I.; Ohki, S.; Tokumine, M.; Matsumoto, K.; Morishita, Y. Effects of adding P38 mitogen-activated protein-kinase inhibitor to celsior solution in canine heart transplantation from non-heart-beating donors. Transplantation 2004, 77, 286-292.

57. Hashimoto, N.; Takeyoshi, I.; Tsutsumi, H.; Sunose, Y.; Tokumine, M.; Totsuka, O.; Ohwada, S.; Matsumoto, K.; Morishita, Y. Effects of a bradykinin B(2) receptor antagonist on ischemia-reperfusion injury in a canine lung transplantation model. J. Heart Lung Transplant. 2004, 23, 606-613.

58. Wang, H.; Sun, X.; Xu, Y.; Zhao, H.; Zhu, Q.; Zhu, C. Astaxanthin upregulates heme oxygenase-1 expression through ERK1/2 pathway and its protective effect against beta-amyloid-induced cytotoxicity in SH-SY5Y cells. Brain Res. 2010, 1360, 159-167.

59. Cheng, P.; Wang, F.; Chen, K.; Shen, M.; Dai, W.; Xu, L.; Zhang, Y.; Wang, C.; Li, J.; Yang, J.; et al. Hydrogen sulfide ameliorates ischemia/reperfusion-induced hepatitis by inhibiting apoptosis and autophagy pathways. Mediators Inflamm. 2014, 2014, doi:10.1155/2014/935251.

60. Wang, C.; Chen, K.; Xia, Y.; Dai, W.; Wang, F.; Shen, M.; Cheng, P.; Wang, J.; Lu, J.; Zhang, Y.; et al. $\mathrm{N}$-Acetylcysteine Attenuates Ischemia-Reperfusion-Induced Apoptosis and Autophagy in Mouse Liver via Regulation of the ROS/JNK/Bcl-2 Pathway. PLoS ONE 2014, 9, e108855.

61. Park, G.B.; Choi, Y.; Kim, Y.S.; Lee, H.K.; Kim, D.; Hur, D.Y. ROS-mediated JNK/p38-MAPK activation regulates Bax translocation in Sorafenib-induced apoptosis of EBV-transformed B cells. Int. J. Oncol. 2014, 44, 977-985.

62. Park, G.B.; Kim, Y.S.; Lee, H.K.; Song, H.; Kim, S.; Cho, D.H.; Hur, D.Y. Reactive oxygen species and p38 MAPK regulate Bax translocation and calcium redistribution in salubrinal-induced apoptosis of EBV-transformed B cells. Cancer Lett. 2011, 313, 235-248.

63. Malik, S.; Suchal, K.; Gamad, N.; Dinda, A.K.; Arya, D.S.; Bhatia, J. Telmisartan ameliorates cisplatin-induced nephrotoxicity by inhibiting MAPK mediated inflammation and apoptosis. Eur. J. Pharmacol. 2014, 748, 54-60.

64. Ishiki, M.; Nishida, Y.; Ishibashi, H.; Wada, T.; Fujisaka, S.; Takikawa, A.; Urakaze, M.; Sasaoka, T.; Usui, I.; Tobe, K. Impact of divergent effects of astaxanthin on insulin signaling in L6 cells. Endocrinology 2013, 154, 2600-2612.

65. Camera, E.; Mastrofrancesco, A.; Fabbri, C.; Daubrawa, F.; Picardo, M.; Sies, H.; Stahl, W. Astaxanthin, canthaxanthin and beta-carotene differently affect UVA-induced oxidative damage and expression of oxidative stress-responsive enzymes. Exp. Dermatol. 2009, 18, 222-231.

66. Gordy, C.; He, Y.W. The crosstalk between autophagy and apoptosis: Where does this lead? Protein Cell 2012, 3, 17-27.

67. Lin, X.; Li, S.; Zhao, Y.; Ma, X.; Zhang, K.; He, X.; Wang, Z. Interaction domains of p62: A bridge between p62 and selective autophagy. DNA Cell Biol. 2013, 32, 220-227.

68. Abe, Y.; Hines, I.N.; Zibari, G.; Pavlick, K.; Gray, L.; Kitagawa, Y.; Grisham, M.B. Mouse model of liver ischemia and reperfusion injury: Method for studying reactive oxygen and nitrogen metabolites in vivo. Free Radic. Biol. Med. 2009, 46, 1-7.

(C) 2015 by the authors; licensee MDPI, Basel, Switzerland. This article is an open access article distributed under the terms and conditions of the Creative Commons Attribution license (http://creativecommons.org/licenses/by/4.0/). 